International Journal of Pure and Applied Mathematics

Volume 89 No. 4 2013, 531-546

ISSN: 1311-8080 (printed version); ISSN: 1314-3395 (on-line version)

url: http://www.ijpam.eu

doi: http://dx.doi.org/10.12732/ijpam.v89i4.7

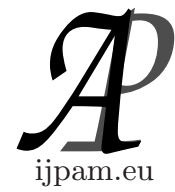

\title{
COINCIDENCE POINTS AND FIXED POINT THEOREMS FOR MULTI-VALUED MAPPINGS ON PARTIAL METRIC SPACES
}

\author{
Anchalee Kaewcharoen ${ }^{1}$, Tadchai Yuying ${ }^{2}$ \\ ${ }^{1,2}$ Department of Mathematics \\ Faculty of Science \\ Naresuan University \\ Phisanulok, 65000, THAILAND
}

AMS Subject Classification: 47H10, 54H25

Key Words: common fixed points, coincidence points, multi-valued mappings, partial metric spaces

\section{Introduction and Preliminaries}

In 1969, Nadler [11] assured the multi-valued version of Banach contraction principle. Since then the metric fixed point theory of single-valued mappings has been extended to multi-valued mappings. In 1994, Matthews [9] introduced the partial metric spaces and proved the Banach contraction principle in such spaces. Many authors have studied the fixed point theorems for mappings satisfying some contractive conditions in complete partial metric spaces (see [3], [4], [5, 6], [7], [8] and references contained therein). In 2012, Aydi et al. [7] introduced the definition of a partial Hausdorff metric and also proved the existence of the Banach contraction principle for multi-valued mappings in complete partial metric spaces. Recently, they [8] proved the common fixed point theorem for multi-valued mappings satisfying generalized contractive condition in complete partial metric spaces.

Received: August 17, 2013

(c) 2013 Academic Publications, Ltd.

$\S$ Correspondence author url: www.acadpubl.eu 
Matthews [9] gave the definition of partial metric spaces as the following.

Definition 1. A partial metric on a nonempty set $X$ is a function $p$ : $X \times X \rightarrow \mathbb{R}^{+}$such that for all $x, y, z \in X$,

(P1) $x=y$ if and only if $p(x, x)=p(x, y)=p(y, y)$;

(P2) $p(x, x) \leq p(x, y)$;

(P3) $p(x, y)=p(y, x)$;

(P4) $p(x, z) \leq p(x, y)+p(y, z)-p(y, y)$.

A pair $(X, p)$ is called a partial metric space and $p$ is a partial metric on $X$.

For each partial metric $p$ on $X$, the function $p^{s}: X \times X \rightarrow \mathbb{R}^{+}$defined by

$$
p^{s}(x, y)=2 p(x, y)-p(x, x)-p(y, y)
$$

is a usual metric on $X$.

Definition 2. Let $(X, p)$ be a partial metric space.

(1) A sequence $\left\{x_{n}\right\}$ in a partial metric space $(X, p)$ converges to a point $x \in X$ if $\lim _{n \rightarrow \infty} p\left(x, x_{n}\right)=p(x, x)$.

(2) A sequence $\left\{x_{n}\right\}$ in a partial metric space $(X, p)$ is called a Cauchy sequence if $\lim _{n, m \rightarrow \infty} p\left(x_{n}, x_{m}\right)$ exists (and is finite).

(3) A partial metric space $(X, p)$ is said to be complete if every Cauchy sequence $\left\{x_{n}\right\}$ in $X$ converges, with respect to $\tau_{p}$, to a point $x \in X$ such that $\lim _{n, m \rightarrow \infty} p\left(x_{n}, x_{m}\right)=p(x, x)$.

Lemma 3. [9] Let $(X, p)$ be a partial metric space. Then

(1) A sequence $\left\{x_{n}\right\}$ in a partial metric space $(X, p)$ is a Cauchy sequence if and only if it is a Cauchy sequence in the metric space $\left(X, p^{s}\right)$.

(2) A partial metric space $(X, p)$ is complete if and only if the metric space $\left(X, p^{s}\right)$ is complete. Moreover,

$$
\lim _{n \rightarrow \infty} p^{s}\left(x, x_{n}\right)=0 \text { iff } \lim _{n \rightarrow \infty} p\left(x, x_{n}\right)=\lim _{n, m \rightarrow \infty} p\left(x_{n}, x_{m}\right)=p(x, x) .
$$

(3) A subset $E$ of a partial metric space $(X, p)$ is closed if whenever $\left\{x_{n}\right\}$ is a sequence in $E$ such that $\left\{x_{n}\right\}$ converges to some $x \in X$, then $x \in E$. 
Lemma 4. [2] Let $(X, p)$ be a partial metric space. Then

(1) If $p(x, y)=0$, then $x=y$.

(2) If $x \neq y$, then $p(x, y)>0$.

In 2012, Aydi et al. [7] defined a partial Hausdorff metric as follows.

Let $(X, p)$ be a partial metric space. Let $C B^{p}(X)$ be the family of all nonempty closed and bounded subsets of the partial metric space $(X, p)$. For any $A, B \in C B^{p}(X)$ and $x \in X$, define

$$
\delta_{p}(B, A)=\sup \{p(b, A): b \in B\} \text { and } \delta_{p}(A, B)=\sup \{p(a, B): a \in A\},
$$

where

$$
p(x, A)=\inf \{p(x, a), a \in A\} .
$$

The mapping $H_{p}: C B^{p}(X) \times C B^{p}(X) \rightarrow[0,+\infty)$ defined by

$$
H_{p}(A, B)=\max \left\{\delta_{p}(A, B), \delta_{p}(B, A)\right\}
$$

is called a partial Hausdorff metric induced by $p$.

Remark 5. [3] Let $(X, p)$ be a partial metric space. If $A$ is a nonempty set in $(X, p)$, then

$$
a \in \bar{A} \text { if and only if } p(a, A)=p(a, a),
$$

where $\bar{A}$ is the clusure of $A$ with respect to the partial metric $p$.

Proposition 6. [7] Let $(X, p)$ be a partial metric space. For all $A, B, C \in$ $C B^{p}(X)$, we have

(i) $\delta_{p}(A, A)=\sup \{p(a, a): a \in A\}$;

(ii) $\delta_{p}(A, A) \leq \delta_{p}(A, B)$;

(iii) $\delta_{p}(A, B)$ implies that $A \subseteq B$;

(iv) $\delta_{p}(A, B) \leq \delta_{p}(A, C)+\delta_{p}(C, B)-\inf _{c \in C} p(c, c)$.

Proposition 7. [7] Let $(X, p)$ be a partial metric space. For all $A, B, C \in$ $C B^{p}(X)$, we have

(i) $H_{p}(A, A) \leq H_{p}(A, B)$;

(ii) $H_{p}(A, B)=H_{p}(B, A)$; 
(iii) $H_{p}(A, B) \leq H_{p}(A, C)+H_{p}(C, B)-\inf _{c \in C} p(c, c)$.

Corollary 8. [7] Let $(X, p)$ be a partial metric space. For all $A, B \in$ $C B^{p}(X)$, we have

$$
H_{p}(A, B)=0 \text { implies that } A=B \text {. }
$$

Definition 9. An element $x \in X$ is said to be a fixed point of a multivalued mapping $T: X \rightarrow C B^{p}(X)$ if $x \in T x$. An element $x \in X$ is called a common fixed point of two multi-valued mappings $T, S: X \rightarrow C B^{p}(X)$ if $x \in T x \cap S x$.

Definition 10. Let $X$ be a set. Assume that $g: X \rightarrow X$ and $T: X \rightarrow 2^{X}$. If $w=g x \in T x$ for some $x \in X$, then $x$ is called a coincidence point of $g$ and $T$. An element $w$ is called a point of coincidence of $g$ and $T$.

In 1989, Mizoguchi and Takahashi [10] proved the generalization of Banach contraction principle in complete metric spaces as the following:

Theorem 11. ([10, Theorem 5]) Let $(X, d)$ be a complete metric space and $T: X \rightarrow C B(X)$ be a multi-valued mapping satisfying

$$
H(T x, T y) \leq \varphi(d(x, y)) d(x, y)
$$

for all $x, y \in X$ where $\varphi:[0, \infty) \rightarrow[0,1)$ is a mapping such that $\lim \sup _{r \rightarrow t^{+}} \varphi(r)$ $<1$ for every $t \in[0, \infty)$. Then $T$ has a fixed point in $X$.

In 2012, Aydi et al. [7] proved the fixed point theorem for multi-valued mappings in complete partial metric spaces as the following:

Theorem 12. [7] Let $(X, p)$ be a complete partial metric space. Suppose that $T: X \rightarrow C B^{p}(X)$ is a multi-valued mapping satisfying

$$
H_{p}(T x, T y) \leq k p(x, y)
$$

for all $x, y \in X$ where $k \in[0,1)$. Then $T$ has a fixed point.

Recently in 2013, Aydi et al. [8] assured the existence of the common fixed point theorem for multi-valued mappings in complete partial metric spaces using the following lemma as a tool.

Lemma 13. [8] Let $A, B \in C B^{p}(X)$ and $a \in A$. Then, for $\varepsilon>0$, there exists a point $b \in B$ such that $p(a, b) \leq H_{p}(A, B)+\varepsilon$. 
Theorem 14. [8] Let $(X, p)$ be a complete partial metric space. Suppose that $T, S: X \rightarrow C B^{p}(X)$ are multi-valued mappings satisfying

$$
H_{p}(T x, T y) \leq \alpha M(x, y),
$$

for all $x, y \in X$ where $\alpha \in[0,1)$ and

$$
M(x, y)=\max \left\{p(x, y), p(x, T x), p(y, S y), \frac{1}{2}[p(x, S y)+p(y, T x)]\right\} .
$$

Then $T$ and $S$ have a common fixed point in $X$. Moreover, if $T$ or $S$ is a single-valued mapping, then $T$ and $S$ have a unique common fixed point.

In this paper, we prove the existence of coincidence points for multi-valued and single-valued mappings satisfying generalized contractive condition appeared in Theorem 11 in complete partial metric spaces. We also prove the common fixed point theorem for multi-valued mappings in complete partial metric spaces where such mappings satisfy the generalized contractive condition. Our results extend Theorem 11, Theorem 12 and Theorem 14.

\section{Common fixed point theorems}

We first prove the following lemma as our tool.

Lemma 15. Let $(X, p)$ be a partial metric space and $A, B \in C B^{p}(X)$. Suppose that $\varepsilon>0$ and $H_{p}(A, B)<\varepsilon$. Then for all $a \in A$ there exists $b \in B$ such that $p(a, b)<\varepsilon$

Proof. Assume that there exists $a \in A$ such that $p(a, b) \geq \varepsilon$ for all $b \in B$. This implies that $p(a, B) \geq \varepsilon$. Therefore $H_{p}(A, B) \geq \varepsilon$ which contradicts to the assumption. This completes the proof.

Theorem 16. Let $(X, p)$ be a partial metric space. Suppose that $T: X \rightarrow$ $C B^{p}(X)$ is a multi-valued mapping and $f: X \rightarrow X$ is a single-valued mapping satisfying the following conditions:

(1) $T(X) \subseteq f(X)$,

(2) $f(X)$ is complete,

(3) there exists a mapping $\varphi:[0, \infty) \rightarrow[0,1)$ such that

$$
\limsup _{r \rightarrow t^{+}} \varphi(r)<1 \text { for all } t \in[0, \infty),
$$


and for all $x, y \in X$,

$$
H_{p}(T x, T y) \leq \varphi(p(f x, f y)) p(f x, f y) .
$$

Then $T$ and $f$ have a coincidence point in $X$. That is there exists $q \in X$ such that $f q \in T q$.

Proof. Define a function $\omega:[0, \infty) \rightarrow[0,1)$ such that $\omega(t)=\frac{\varphi(t)+1}{2}$, for all $t \in[0, \infty)$. This implies that

$$
\limsup _{r \rightarrow t^{+}} \omega(r)<1, \varphi(t)<\omega(t) \text { and } 0<\omega(t)<1 \text {, for all } t \in[0, \infty) .
$$

Let $x_{0}$ be an arbitrary element in $X$. Since $T(X) \subseteq f(X)$, there exists $x_{1} \in X$ such that $f x_{1} \in T x_{0}$. By applying (3), we obtain that

$$
\begin{aligned}
H_{p}\left(T x_{0}, T x_{1}\right) & \leq \varphi\left(p\left(f x_{0}, f x_{1}\right)\right) p\left(f x_{0}, f x_{1}\right) \\
& <\omega\left(p\left(f x_{0}, f x_{1}\right)\right) p\left(f x_{0}, f x_{1}\right) .
\end{aligned}
$$

If $f x_{0}=f x_{1}$, then $T$ and $f$ have a coincidence point. Assume that $f x_{0} \neq f x_{1}$. By Lemma 15, there exists $f x_{2} \in T x_{1}$ such that

$$
p\left(f x_{1}, f x_{2}\right)<\omega\left(p\left(f x_{0}, f x_{1}\right)\right) p\left(f x_{0}, f x_{1}\right) .
$$

By continuing the process as above, we can construct a sequence $\left\{f x_{n}\right\}$ such that $f x_{n} \in T x_{n-1}$ and

$$
p\left(f x_{n}, f x_{n+1}\right)<\omega\left(p\left(f x_{n-1}, f x_{n}\right)\right) p\left(f x_{n-1}, f x_{n}\right)
$$

for each $n \in \mathbb{N}$. Since $\omega(t)<1$ for all $t \in[0, \infty)$, we have

$$
p\left(f x_{n}, f x_{n+1}\right)<p\left(f x_{n-1}, f x_{n}\right), \text { for all } n \in \mathbb{N} .
$$

It follows that $\left\{p\left(f x_{n}, f x_{n+1}\right)\right\}$ is a nonincreasing sequence in $[0, \infty)$. Therefore $\left\{p\left(f x_{n}, f x_{n+1}\right)\right\}$ is convergent. Since $\limsup _{r \rightarrow t^{+}} \omega(r)<1$, we obtain that

$$
\limsup _{n \rightarrow \infty} \omega\left(p\left(f x_{n}, f x_{n+1}\right)\right)=s \text { for some } s \in[0,1) .
$$

This implies that for each $k \in(s, 1)$, there is $N \in \mathbb{N}$ such that

$$
\omega\left(p\left(f x_{n-1}, f x_{n}\right)\right)<k, \text { for all } n \geq N .
$$

For each $n \geq N$, we obtain that

$$
p\left(f x_{n}, f x_{n+1}\right)<\omega\left(p\left(f x_{n-1}, f x_{n}\right)\right) p\left(f x_{n-1}, f x_{n}\right)
$$




$$
<k p\left(f x_{n-1}, f x_{n}\right) .
$$

Thus for each $m>n \geq N$, we have

$$
\begin{aligned}
p\left(f x_{n}, f x_{m}\right) \leq & {\left[p\left(f x_{n}, f x_{n+1}\right)+p\left(f x_{n+1}, f x_{n+2}\right)+\cdots+p\left(f x_{m-1}, f x_{m}\right)\right]-} \\
& {\left[p\left(f x_{n+1}, f x_{n+1}\right)+p\left(f x_{n+2}, f x_{n+2}\right)+\cdots+p\left(f x_{m-1}, f x_{m-1}\right)\right] } \\
\leq & p\left(f x_{n}, f x_{n+1}\right)+p\left(f x_{n+1}, f x_{n+2}\right)+\cdots+p\left(f x_{m-1}, f x_{m}\right) \\
\leq & {\left[k^{n-N}+k^{n-N+1}+\cdots+k^{m-N-1}\right] p\left(f x_{N}, f x_{N+1}\right) } \\
\leq & \frac{k^{n-N}}{1-k} p\left(f x_{N}, f x_{N+1}\right) .
\end{aligned}
$$

Therefore

$$
\lim _{n, m \rightarrow \infty} p\left(f x_{n}, f x_{m}\right)=0 .
$$

By applying (1), we have

$$
\begin{aligned}
p^{s}\left(f x_{n}, f x_{m}\right) & =2 p\left(f x_{n}, f x_{m}\right)-p\left(f x_{m}, f x_{m}\right)-p\left(f x_{n}, f x_{n}\right) \\
& \leq 2 p\left(f x_{n}, f x_{m}\right) .
\end{aligned}
$$

Applying (4), this yields

$$
\lim _{n, m \rightarrow \infty} p^{s}\left(f x_{n}, f x_{m}\right)=0 .
$$

This implies that $\left\{f x_{n}\right\}$ is a Cauchy sequence in $\left(X, p^{s}\right)$. By the completeness of $f(X)$, we have $\left\{f x_{n}\right\}$ is convergent to some $u \in X$. Therefore there exists $q \in X$ such that $u=f q$. That is

$$
\lim _{n \rightarrow \infty} f x_{n}=f q .
$$

By Lemma 3 and (6), we obtain that

$$
p(f q, f q)=\lim _{n \rightarrow \infty} p\left(f x_{n}, f q\right)=\lim _{n, m \rightarrow \infty} p\left(f x_{n}, f x_{m}\right) .
$$

From (4) and (7), we can conclude that $p(f q, f q)=0$. Therefore, for each $n \in \mathbb{N}$, we have

$$
\begin{aligned}
p\left(f x_{n+1}, T q\right) & \leq H_{p}\left(T x_{n}, T q\right) \\
& \leq \varphi\left(p\left(f x_{n}, f q\right)\right) p\left(f x_{n}, f q\right) \\
& <p\left(f x_{n}, f q\right) .
\end{aligned}
$$

By taking the limit as $n \rightarrow \infty$ and $p(f q, f q)=0$, we have $p(f q, T q)=0$ Therefore $f q \in T q$. Hence $T$ and $f$ have a coincident point. 
Using Theorem 16, we immediately obtain the following corollary proved in [10].

Corollary 17. ([10, Theorem 5]) Let $(X, d)$ be a complete metric space. Suppose that $T: X \rightarrow C B(X)$ is a multi-valued mapping satisfying

$$
H(T x, T y) \leq \varphi(d(x, y)) d(x, y)
$$

for all $x, y \in X$ where $\varphi:[0, \infty) \rightarrow[0,1)$ is a mapping such that $\lim \sup _{r \rightarrow t^{+}} \varphi(r)$ $<1$ for every $t \in[0, \infty)$. Then $T$ has a fixed point in $X$.

Corollary 18. Let $(X, p)$ be a partial metric space. Suppose that $T$ : $X \rightarrow C B^{p}(X)$ is a multi-valued mapping and $f: X \rightarrow X$ is a single-valued mapping satisfying the following conditions:

(1) $T(X) \subseteq f(X)$,

(2) $f(X)$ is complete,

(3) $H_{p}(T x, T y) \leq k p(f x, f y)$, for all $x, y \in X$ where $k \in[0,1)$

Then $T$ and $f$ have a coincidence point in $X$. That is there exists $q \in X$ such that $f q \in T q$.

Proof. Define $\varphi:[0, \infty) \rightarrow[0,1)$ by $\varphi(t)=k$ for all $t \in[0, \infty)$. It follows that all assumptions in Theorem 16 are now satisfied. Hence the proof is complete.

Letting $f$ in Corollary 18 to be an identity mapping defined on $X$, we immediately obtain the following corollary:

Corollary 19. (Theorem 3.2, [7]) Let $(X, p)$ be a complete partial metric space. Suppose that $T: X \rightarrow C B^{p}(X)$ is a multi-valued mapping satisfying

$$
H_{p}(T x, T y) \leq k p(x, y)
$$

for all $x, y \in X$ where $k \in[0,1)$. Then $T$ has a fixed point.

We now assure the existence of the common fixed point theorem for multivalued mappings in complete partial metric spaces by using the combination of techniques appeared in [1] and [8]. 
Theorem 20. Let $(X, p)$ be a complete partial metric space. Suppose that $T, S: X \rightarrow C B^{p}(X)$ are multi-valued mappings satisfying

$$
H_{p}(T x, S y) \leq \alpha M(x, y)+L \min \{p(x, T x), p(y, S y), p(x, S y), p(y, T x)\},
$$

for all $x, y \in X$ where $\alpha \in[0,1), L \geq 0, \alpha+2 L<1$, and

$$
M(x, y)=\max \left\{p(x, y), p(x, T x), p(y, S y), \frac{1}{2}[p(x, S y)+p(y, T x)]\right\} .
$$

Then $T$ and $S$ have a common fixed point. Moreover, if $T$ or $S$ is a single-valued mapping, then $T$ and $S$ have a unique common fixed point.

Proof. Let $\varepsilon>0$ be such that $\alpha+\varepsilon+2 L<1$. Let $x_{0} \in X$ and $x_{1} \in S x_{0}$. It is easily seen that, if $M\left(x_{1}, x_{0}\right)=0$, then $x_{1}=x_{0}$ and $x_{0}$ is a common fixed point of $T$ and $S$. Suppose that $M\left(x_{1}, x_{0}\right)>0$. By Lemma 13, there exists $x_{2} \in T x_{1}$ such that

$$
p\left(x_{2}, x_{1}\right) \leq H_{p}\left(T x_{1}, S x_{0}\right)+\varepsilon M\left(x_{1}, x_{0}\right) .
$$

If $M\left(x_{2}, x_{1}\right)=0$, then $x_{2}=x_{1}$ and $x_{1}$ is a common fixed point of $T$ and $S$. We assume that $M\left(x_{2}, x_{1}\right)>0$. By Lemma 13 , there exists $x_{3} \in S x_{2}$ such that

$$
p\left(x_{3}, x_{2}\right) \leq H_{p}\left(S x_{2}, T x_{1}\right)+\varepsilon M\left(x_{2}, x_{1}\right) .
$$

Continuing the process as above, we can construct a sequence $\left\{x_{n}\right\}$ in $X$ such that $x_{2 n+1} \in S x_{2 n}$ and $x_{2 n+2} \in T x_{2 n+1}$ and $M\left(x_{n}, x_{n-1}\right)>0$ with

$$
p\left(x_{2 n+1}, x_{2 n}\right) \leq H_{p}\left(S x_{2 n}, T x_{2 n-1}\right)+\varepsilon M\left(x_{2 n}, x_{2 n-1}\right)
$$

and

$$
p\left(x_{2 n+2}, x_{2 n+1}\right) \leq H_{p}\left(T x_{2 n+1}, S x_{2 n}\right)+\varepsilon M\left(x_{2 n+1}, x_{2 n}\right) .
$$

By applying (9), we obtain that

$$
\begin{aligned}
p\left(x_{2 n+1}, x_{2 n}\right) \leq & H_{p}\left(T x_{2 n-1}, S x_{2 n}\right)+\varepsilon M\left(x_{2 n-1}, x_{2 n}\right) \\
\leq & \alpha M\left(x_{2 n-1}, x_{2 n}\right)+\varepsilon M\left(x_{2 n-1}, x_{2 n}\right)+ \\
& L \min \left\{p\left(x_{2 n-1}, T x_{2 n-1}\right), p\left(x_{2 n}, S x_{2 n}\right), p\left(x_{2 n-1}, S x_{2 n}\right),\right. \\
& \left.p\left(x_{2 n}, T x_{2 n-1}\right)\right\} \\
= & (\alpha+\varepsilon) M\left(x_{2 n-1}, x_{2 n}\right)+ \\
& L \min \left\{p\left(x_{2 n-1}, T x_{2 n-1}\right), p\left(x_{2 n}, S x_{2 n}\right), p\left(x_{2 n-1}, S x_{2 n}\right),\right. \\
& \left.p\left(x_{2 n}, T x_{2 n-1}\right)\right\} .
\end{aligned}
$$


Since

$$
\begin{aligned}
M\left(x_{2 n-1}, x_{2 n}\right)= & \max \left\{p\left(x_{2 n-1}, x_{2 n}\right), p\left(x_{2 n-1}, T x_{2 n-1}\right), p\left(x_{2 n}, S x_{2 n}\right),\right. \\
& \left.\frac{1}{2}\left[p\left(x_{2 n-1}, S x_{2 n}\right)+p\left(x_{2 n}, T x_{2 n-1}\right)\right]\right\} \\
\leq & \max \left\{p\left(x_{2 n-1}, x_{2 n}\right), p\left(x_{2 n-1}, x_{2 n}\right), p\left(x_{2 n}, x_{2 n+1}\right),\right. \\
& \left.\frac{1}{2}\left[p\left(x_{2 n-1}, x_{2 n+1}\right)+p\left(x_{2 n}, x_{2 n}\right)\right]\right\} \\
= & \max \left\{p\left(x_{2 n-1}, x_{2 n}\right), p\left(x_{2 n}, x_{2 n+1}\right),\right. \\
& \left.\frac{1}{2}\left[p\left(x_{2 n-1}, x_{2 n+1}\right)+p\left(x_{2 n}, x_{2 n}\right)\right]\right\} \\
\leq & \max \left\{p\left(x_{2 n-1}, x_{2 n}\right), p\left(x_{2 n}, x_{2 n+1}\right)\right\}
\end{aligned}
$$

and

$$
\begin{aligned}
\min \left\{p\left(x_{2 n-1}, T x_{2 n-1}\right), p\left(x_{2 n}, S x_{2 n}\right), p\left(x_{2 n-1}, S x_{2 n}\right), p\left(x_{2 n}, T x_{2 n-1}\right)\right\} \\
\quad \leq \min \left\{p\left(x_{2 n-1}, x_{2 n}\right), p\left(x_{2 n}, x_{2 n+1}\right), p\left(x_{2 n-1}, x_{2 n+1}\right), p\left(x_{2 n}, x_{2 n}\right)\right\} \\
\quad=\min \left\{p\left(x_{2 n-1}, x_{2 n+1}\right), p\left(x_{2 n}, x_{2 n}\right)\right\}
\end{aligned}
$$

we obtain that

$$
\begin{aligned}
p\left(x_{2 n+1}, x_{2 n}\right) \leq & (\alpha+\varepsilon) \max \left\{p\left(x_{2 n-1}, x_{2 n}\right), p\left(x_{2 n}, x_{2 n+1}\right)\right\}+ \\
& L \min \left\{p\left(x_{2 n-1}, x_{2 n+1}\right), p\left(x_{2 n}, x_{2 n}\right)\right\} .
\end{aligned}
$$

We separate the proof into the following cases.

Case I : If $\max \left\{p\left(x_{2 n-1}, x_{2 n}\right), p\left(x_{2 n}, x_{2 n+1}\right)\right\}=p\left(x_{2 n-1}, x_{2 n}\right)$ and $\min \left\{p\left(x_{2 n-1}, x_{2 n+1}\right), p\left(x_{2 n}, x_{2 n}\right)\right\}=p\left(x_{2 n-1}, x_{2 n+1}\right)$, then

$$
\begin{aligned}
p\left(x_{2 n+1}, x_{2 n}\right) \leq & (\alpha+\varepsilon) p\left(x_{2 n-1}, x_{2 n}\right)+L p\left(x_{2 n-1}, x_{2 n+1}\right) \\
\leq & (\alpha+\varepsilon) p\left(x_{2 n-1}, x_{2 n}\right)+L\left(p\left(x_{2 n-1}, x_{2 n}\right)\right. \\
& \left.+p\left(x_{2 n}, x_{2 n+1}\right)-p\left(x_{2 n}, x_{2 n}\right)\right) \\
\leq & (\alpha+\varepsilon) p\left(x_{2 n-1}, x_{2 n}\right)+L p\left(x_{2 n-1}, x_{2 n}\right)+L p\left(x_{2 n}, x_{2 n+1}\right) .
\end{aligned}
$$

It follows that

$$
p\left(x_{2 n+1}, x_{2 n}\right) \leq \frac{(\alpha+\varepsilon)+L}{1-L} p\left(x_{2 n-1}, x_{2 n}\right)
$$

Let $\beta_{1}=\frac{(\alpha+\varepsilon)+L}{1-L}$. Since $(\alpha+\varepsilon)+2 L<1$, we have $\beta_{1}<1$. Therefore

$$
p\left(x_{2 n}, x_{2 n+1}\right) \leq \beta_{1} p\left(x_{2 n-1}, x_{2 n}\right) .
$$


Case II : If $\max \left\{p\left(x_{2 n-1}, x_{2 n}\right), p\left(x_{2 n}, x_{2 n+1}\right)\right\}=p\left(x_{2 n-1}, x_{2 n}\right)$ and $\min \left\{p\left(x_{2 n-1}, x_{2 n+1}\right), p\left(x_{2 n}, x_{2 n}\right)\right\}=p\left(x_{2 n}, x_{2 n}\right)$, then

$$
\begin{aligned}
p\left(x_{2 n+1}, x_{2 n}\right) & \leq(\alpha+\varepsilon) p\left(x_{2 n-1}, x_{2 n}\right)+\operatorname{Lp}\left(x_{2 n}, x_{2 n}\right) \\
& \leq(\alpha+\varepsilon) p\left(x_{2 n-1}, x_{2 n}\right)+\operatorname{Lp}\left(x_{2 n}, x_{2 n+1}\right) .
\end{aligned}
$$

This implies that

$$
p\left(x_{2 n+1}, x_{2 n}\right) \leq \frac{(\alpha+\varepsilon)}{1-L} p\left(x_{2 n-1}, x_{2 n}\right) .
$$

Let $\beta_{2}=\frac{(\alpha+\varepsilon)}{1-L}$. Since $(\alpha+\varepsilon)+2 L<1$, we have $\beta_{2}<1$. Therefore

$$
p\left(x_{2 n}, x_{2 n+1}\right) \leq \beta_{2} p\left(x_{2 n-1}, x_{2 n}\right) .
$$

Case III : If $\max \left\{p\left(x_{2 n-1}, x_{2 n}\right), p\left(x_{2 n}, x_{2 n+1}\right)\right\}=p\left(x_{2 n}, x_{2 n+1}\right)$ and $\min \left\{p\left(x_{2 n-1}, x_{2 n+1}\right), p\left(x_{2 n}, x_{2 n}\right)\right\}=p\left(x_{2 n-1}, x_{2 n+1}\right)$, then

$$
\begin{aligned}
p\left(x_{2 n+1}, x_{2 n}\right) \leq & (\alpha+\varepsilon) p\left(x_{2 n}, x_{2 n+1}\right)+L p\left(x_{2 n-1}, x_{2 n+1}\right) \\
\leq & (\alpha+\varepsilon) p\left(x_{2 n}, x_{2 n+1}\right)+L\left(p\left(x_{2 n-1}, x_{2 n}\right)\right. \\
& \left.+p\left(x_{2 n}, x_{2 n+1}\right)-p\left(x_{2 n}, x_{2 n}\right)\right) \\
\leq & (\alpha+\varepsilon) p\left(x_{2 n}, x_{2 n+1}\right)+L p\left(x_{2 n-1}, x_{2 n}\right)+L p\left(x_{2 n}, x_{2 n+1}\right) .
\end{aligned}
$$

This implies that

$$
p\left(x_{2 n+1}, x_{2 n}\right) \leq \frac{L}{1-(\alpha+\varepsilon+L)} p\left(x_{2 n-1}, x_{2 n}\right) .
$$

Let $\beta_{3}=\frac{L}{1-(\alpha+\varepsilon+L)}$. Since $(\alpha+\varepsilon)+2 L<1$, we have $\beta_{3}<1$. Therefore

$$
p\left(x_{2 n}, x_{2 n+1}\right) \leq \beta_{3} p\left(x_{2 n-1}, x_{2 n}\right) .
$$

Case IV : If $\max \left\{p\left(x_{2 n-1}, x_{2 n}\right), p\left(x_{2 n}, x_{2 n+1}\right)\right\}=p\left(x_{2 n}, x_{2 n+1}\right)$ and $\min \left\{p\left(x_{2 n-1}, x_{2 n+1}\right), p\left(x_{2 n}, x_{2 n}\right)\right\}=p\left(x_{2 n}, x_{2 n}\right)$, then

$$
\begin{aligned}
p\left(x_{2 n+1}, x_{2 n}\right) & \leq(\alpha+\varepsilon) p\left(x_{2 n}, x_{2 n+1}\right)+L p\left(x_{2 n}, x_{2 n}\right) \\
& \leq(\alpha+\varepsilon) p\left(x_{2 n}, x_{2 n+1}\right)+\operatorname{Lp}\left(x_{2 n-1}, x_{2 n}\right) .
\end{aligned}
$$

This implies that

$$
p\left(x_{2 n+1}, x_{2 n}\right) \leq \frac{L}{1-(\alpha+\varepsilon)} p\left(x_{2 n-1}, x_{2 n}\right) .
$$


Let $\beta_{4}=\frac{L}{1-(\alpha+\varepsilon)}$. Since $(\alpha+\varepsilon)+2 L<1$, we have $\beta_{4}<1$. Therefore

$$
p\left(x_{2 n+1}, x_{2 n}\right) \leq \beta_{4} p\left(x_{2 n-1}, x_{2 n}\right) .
$$

Choose $\beta=\max \left\{\beta_{1}, \beta_{2}, \beta_{3}, \beta_{4}\right\}$. Therefore $0<\beta<1$. For each $n \in \mathbb{N}$, we obtain that

$$
p\left(x_{2 n+1}, x_{2 n}\right) \leq \beta p\left(x_{2 n-1}, x_{2 n}\right) .
$$

Using a similar argument as before, we obtain that

$$
p\left(x_{2 n+2}, x_{2 n+1}\right) \leq \beta p\left(x_{2 n+1}, x_{2 n}\right) .
$$

From (11) and (12), we can conclude that

$$
p\left(x_{n+1}, x_{n}\right) \leq \beta p\left(x_{n}, x_{n-1}\right) \text { for all } n \in \mathbb{N} .
$$

For each $n \in \mathbb{N}$, we obtain that

$$
p\left(x_{n+1}, x_{n}\right) \leq \beta^{n} p\left(x_{1}, x_{0}\right) .
$$

Let $m, n \in \mathbb{N}$ with $m>n$. By applying (14), we have

$$
\begin{aligned}
p\left(x_{m}, x_{n}\right) \leq & {\left[p\left(x_{n}, x_{n+1}\right)+p\left(x_{n+1}, x_{n+2}\right)+\cdots+p\left(x_{m-1}, x_{m}\right)\right]-} \\
& {\left[p\left(x_{n+1}, x_{n+1}\right)+p\left(x_{n+2}, x_{n+2}\right)+\cdots+p\left(x_{m-1}, x_{m-1}\right)\right] } \\
\leq & p\left(x_{n}, x_{n+1}\right)+p\left(x_{n+1}, x_{n+2}\right)+\cdots+p\left(x_{m-1}, x_{m}\right) \\
\leq & {\left[\beta^{n}+\beta^{n+1}+\cdots+\beta^{m-1}\right] p\left(x_{1}, x_{0}\right) } \\
\leq & \frac{\beta^{n}}{1-\beta} p\left(x_{1}, x_{0}\right) .
\end{aligned}
$$

It follows that

$$
\lim _{n, m \rightarrow \infty} p\left(x_{m}, x_{n}\right)=0 .
$$

Using (1), we have

$$
\begin{aligned}
p^{s}\left(x_{m}, x_{n}\right) & =2 p\left(x_{m}, x_{n}\right)-p\left(x_{m}, x_{m}\right)-p\left(x_{n}, x_{n}\right) \\
& \leq 2 p\left(x_{m}, x_{n}\right) .
\end{aligned}
$$

Applying (15), we obtain that

$$
\lim _{n, m \rightarrow \infty} p^{s}\left(x_{m}, x_{n}\right)=0 .
$$

This implies that $\left\{x_{n}\right\}$ is a Cauchy sequence in $\left(X, p^{s}\right)$. Since $X$ is complete, we have

$$
\lim _{n \rightarrow \infty} x_{n}=z \text { for some } z \in X
$$


By Lemma 3 and (18), we obtain that

$$
p(z, z)=\lim _{n \rightarrow \infty} p\left(x_{n}, z\right)=\lim _{n, m \rightarrow \infty} p\left(x_{m}, x_{n}\right) .
$$

From (17) and (19), we can conclude that $p(z, z)=0$. Therefore

$$
\begin{aligned}
p\left(x_{2 n+2}, S z\right) \leq & H_{p}\left(T x_{2 n+1}, S z\right) \\
\leq & \alpha M\left(x_{2 n+1}, z\right)+L \min \left\{p\left(x_{2 n+1}, T x_{2 n+1}\right), p(z, S z),\right. \\
& \left.p\left(x_{2 n+1}, S z\right), p\left(z, T x_{2 n+1}\right)\right\} \\
\leq & \alpha \max \left\{p\left(x_{2 n+1}, z\right), p\left(x_{2 n+1}, T x_{2 n+1}\right), p(z, S z),\right. \\
& \left.\frac{1}{2}\left[p\left(x_{n+1}, S z\right)+p\left(z, T x_{2 n+1}\right)\right]\right\}+L \min \left\{p\left(x_{2 n+1}, T x_{2 n+1}\right),\right. \\
& \left.p(z, S z), p\left(x_{2 n+1}, S z\right), p\left(z, T x_{2 n+1}\right)\right\} \\
\leq & \alpha \max \left\{p\left(x_{2 n+1}, z\right), p\left(x_{2 n+1}, x_{2 n+2}\right), p(z, S z),\right. \\
& \left.\frac{1}{2}\left[p\left(x_{n+1}, S z\right)+p\left(z, x_{2 n+2}\right)\right]\right\}+L \min \left\{p\left(x_{2 n+1}, x_{2 n+2}\right),\right. \\
& \left.p(z, S z), p\left(x_{2 n+1}, S z\right), p\left(z, x_{2 n+2}\right)\right\} \\
\leq & \alpha \max \left\{p\left(x_{2 n+1}, z\right), p\left(x_{2 n+1}, z\right)+p\left(z, x_{2 n+2}\right)\right. \\
& -p(z, z), p(z, S z), \\
& \left.\frac{1}{2}\left[p\left(x_{n+1}, S z\right)+p\left(z, x_{2 n+2}\right)\right]\right\} \\
& +L \min \left\{p\left(x_{2 n+1}, z\right)+p\left(z, x_{2 n+2}\right)\right. \\
& \left.-p(z, z), p(z, S z), p\left(x_{2 n+1}, S z\right), p\left(z, x_{2 n+2}\right)\right\} \\
\leq & \alpha \max \left\{p\left(x_{2 n+1}, z\right), p\left(x_{2 n+1}, z\right)+p\left(z, x_{2 n+2}\right), p(z, S z),\right. \\
& \left.\frac{1}{2}\left[p\left(x_{n+1}, S z\right)+p\left(z, x_{2 n+2}\right)\right]\right\} \\
+ & L \min \left\{p\left(x_{2 n+1}, z\right)+p\left(z, x_{2 n+2}\right),\right. \\
& \left.p(z, S z), p\left(x_{2 n+1}, S z\right), p\left(z, x_{2 n+2}\right)\right\} . \\
&
\end{aligned}
$$

That is

$$
\begin{aligned}
p\left(x_{2 n+2}, S z\right) \leq & \alpha \max \left\{p\left(x_{2 n+1}, z\right), p\left(x_{2 n+1}, z\right)\right. \\
& +p\left(z, x_{2 n+2}\right), p(z, S z) \\
& \left.\frac{1}{2}\left[p\left(x_{n+1}, S z\right)+p\left(z, x_{2 n+2}\right)\right]\right\}+ \\
& L \min \left\{p\left(x_{2 n+1}, z\right)+p\left(z, x_{2 n+2}\right)\right. \\
& \left.p(z, S z), p\left(x_{2 n+1}, S z\right), p\left(z, x_{2 n+2}\right)\right\} .
\end{aligned}
$$


Since

$$
p\left(x_{n}, S z\right) \leq p\left(x_{n}, z\right)+p(z, S z) \text { and } p(z, S z) \leq p\left(z, x_{n}\right)+p\left(x_{n}, S z\right),
$$

we obtain that

$$
p(z, S z)-p\left(z, x_{n}\right) \leq p\left(x_{n}, S z\right) \leq p\left(x_{n}, z\right)+p(z, S z) .
$$

By taking the limit as $n \rightarrow \infty$ in (21), we have

$$
\lim _{n \rightarrow \infty} p\left(x_{n}, S z\right)=p(z, S z) .
$$

Therefore, taking the limit as $n \rightarrow \infty$ in (20), this yields

$$
p(z, S z) \leq \alpha p(z, S z)
$$

Since $\alpha \in[0,1)$, we obtain that $p(z, S z)=0$. Therefore $z \in S z$. Similarly, we can prove that $z \in T z$. Therefore $T$ and $S$ have a common fixed point. Now we show that the common fixed point is unique if $T$ is a single-valued mapping. Assume that $u \in X$ is another common fixed point of $T$ and $S$. By using (9), we have

$$
\begin{aligned}
p(u, z) \leq & H_{p}(\{u\}, S z) \\
= & H_{p}(\{T u\}, S z) \\
\leq & \alpha \max \left\{p(u, z), p(u, T u), p(z, S z), \frac{1}{2}[p(u, S z)+p(z, T u)]\right\}+ \\
& L \min \{p(u, T u), p(z, S z), p(u, S z), p(z, T u)\} \\
\leq & \alpha \max \left\{p(u, z), p(u, u), p(z, z), \frac{1}{2}[p(u, z)+p(z, u)]\right\}+ \\
& L \min \{p(u, u), p(z, z), p(u, z), p(z, u)\} \\
\leq & \alpha p(u, z) .
\end{aligned}
$$

Since $\alpha \in[0,1)$, then we have $p(u, z)=0$. Hence $u=z$. This implies that $T$ and $S$ have a unique common fixed point.

If a real number $L$ in Theorem 20 is equal to 0 , then we immediately obtain the following result:

Corollary 21. (Theorem 2.2, [8]) Let $(X, p)$ be a complete partial metric space. Suppose that $T, S: X \rightarrow C B^{p}(X)$ are two multi-valued mappings satisfying the following conditions:

$$
H_{p}(T x, S y) \leq \alpha M(x, y)
$$


for all $x, y \in X$ where $\alpha \in[0,1)$ and

$$
M(x, y)=\max \left\{p(x, y), p(x, T x), p(y, S y), \frac{1}{2}[p(x, S y)+p(y, T x)]\right\} .
$$

Then $T$ and $S$ have a common fixed point. Moreover if $T$ or $S$ is a single-valued mapping, then $T$ and $S$ have a unique common fixed point.

\section{Acknowledgments}

The authors would like to express their deep thanks to Naresuan University for the support.

\section{References}

[1] M. Abbas, G.V.R. Babu and G.N. Alemayehu, On common fixed points of weakly compatible mappings satisfying generalized condition (B), Filomat, 25 (2011), 9-19, DOI:10.2298/FIL1102009A.

[2] M. Abbas and G. Jungck, Common fixed point results for noncommuting mappings without continuity in cone metric space, J. Math. Anal. Appl., 341 (2008) 416-420.

[3] I. Altun and H. Simsek, Some fixed point theorems on dualistic partial metric space, J. Adv. Math. Stud., 1 (2008), 1-8.

[4] I. Altun, F. Sola and H. Simsek, Generalized contraction on partial metric spaces. Topology Appl., 157 (2010), 2778-2785.

[5] H. Aydi, Some fixed point results in ordered partial metric spaces, J. Nonlinear Sci. Appl., 4 (2011), 210-217.

[6] H. Aydi, Common fixed point for four maps in ordered partial metric spaces, Fasc. Math., 49 (2012), 15-31.

[7] H. Aydi, M. Abbas and C. Vetro, Partial Hausdorff metric and Nadler's fixed point theorem on partial metric spaces, Topology Appl., 159 (2012), 3234-3242.

[8] H. Aydi, M. Abbas and C. Vetro, Common fixed point for multivalued generalized contractions on partial metric spaces, RACSAM, (2013), 1-19, DOI 10.1007/s13398-013-0120-z. 
[9] S. G. Matthews, Partial metric topology, Proc. 8th Summer Conference on General Topology and Applications, Ann. New York Acad. Sci., 728 (1994), 183-197.

[10] N. Mizoguchi and W. Takahashi, Fixed point theorems for multi-valued mappings on complete metric spaces, J. Math. Anal. Appl., 141 (1989) 177-188.

[11] S. B. Nadler, Jr., Multivalued contraction mappings, Pacific J. Math., 30 (1969) 475-488. 